\title{
SENTIDOS DE SEXUALIDADE ENTRE MULHERES IDOSAS: RELAÇÕES DE GÊNERO, IDEOLOGIAS MECANICISTAS E SUBVERSÃO
}

\author{
SENTIDOS DE LA SEXUALIDAD ENTRE LAS MUJERES MAYORES: \\ LAS RELACIONES DE GÉNERO, LAS IDEOLOGÍAS MECANICISTAS Y \\ SUBVERSIÓN \\ MEANINGS OF SEXUALITY AMONG ELDERLY WOMEN: GENDER \\ RELATIONS, MECHANISTIC IDEOLOGIES AND SUBVERSION
}

http://dx.doi.org/10.1590/1807-0310/2018v30166019

Estephania de Lima Oliveira ${ }^{1}$, André Luiz Machado das Neves ${ }^{2}$ e Iolete Ribeiro da Silva ${ }^{3}$

${ }^{1}$ Faculdade Maurício de Nassau, Manaus/AM, Brasil

${ }^{2}$ Universidade do Estado do Amazonas, Manaus/AM, Brasil

${ }^{3}$ Universidade Federal do Amazonas, Manaus/AM, Brasil

\begin{abstract}
RESUMO
Este artigo teve o objetivo de compreender os sentidos da sexualidade construídos por mulheres idosas. Realizouse pesquisa de campo com abordagem qualitativa de caráter descritivo-exploratório. Os dados, coletados por meio de entrevista semiestruturada, foram analisados a partir da proposta de núcleos de significação para apreensão dos sentidos. Emergiram os seguintes núcleos: Ato sexual: sexo como obrigação, já estamos enjoadas, já queremos é sossego!; Eu não tenho mais aquela vontade: a culpa é da doença; e Eu estou com muita vontade de fazer sexo: eu ainda gosto! Concluiu-se que os sentidos de sexualidade construídos pelas idosas participantes deste estudo evidenciam um claro direcionamento em dois grupos: as mulheres que "não têm mais vontade de fazer sexo" e as que ainda preferem fazê-lo.
\end{abstract}

Palavras-chave: sentidos; sexualidade; gênero; mulher, terceira idade.

\section{RESUMEN}

Este artículo pretende comprender los significados de la sexualidad para las mujeres mayores. Se realizó una investigación de campo con enfoque cualitativo de carácter descriptivo exploratorio. Los datos, recogidos mediante entrevista semiestructurada, fueron analizados desde el movimiento de los núcleos de significado para comprensión de los sentidos. Surgieron los siguientes núcleos: El acto sexual: sexo como obligación, ya estamos hartas, ¡queremos estar tranquilas!; No tengo más ese impulso: es culpa de la enfermedad; y Tengo muchas ganas de tener sexo: todavía me gusta. Se concluyó que los sentidos de sexualidad construidos por las señoras mayores participantes del estudio ponen en evidencia dos grupos: las mujeres que "no tienen más ganas de tener sexo", y las que aún expresan el deseo de tenerlo.

Palabras clave: sentidos; sexualidad; género; mujer; tercera edad.

\begin{abstract}
This article aims to understand the meanings of sexuality built by elderly women. We performed field research with a qualitative approach of descriptive-exploratory character. The data, collected through a semi-structured interview, were analyzed from the proposed nuclei of meaning for assimilation of the senses. As a result, the following nuclei emerged: sexual intercourse: sex as obligation, we're already tired of it, we want quietness now!; I don't have that urge anymore: it's because of the disease; and I'm eager to have sex: I still like. It was concluded that the senses of sexuality of the elderly women who participated in the study could be divided into two groups: women who "have no longer a desire to have sex" and those who still want to do it.
\end{abstract}

Keywords: senses; sexuality; gender; woman, elderly.

(ec) [1 


\section{Introdução}

O envelhecimento traz alterações importantes nos aspectos físicos e emocionais das pessoas. Porém, os sentimentos e as sensações não se modificam com a idade. A sexualidade, por exemplo, pode ser vivida nessa fase da vida. Neste artigo, a sexualidade é entendida numa perspectiva ampla, não se limitando ao ato sexual ou ao coito. É vista como uma manifestação presente em todas as fases da vida de um ser humano.

Contudo, a sociedade, muitas vezes investida de valores morais e de preconceitos, considera a pessoa idosa como um ser "assexuado". Chega-se a dizer, jocosamente, que existem três sexos: o feminino, o masculino e o sexagenário (Vitiello \& Conceição, 1993).

Ressalte-se ainda que a pessoa idosa de hoje foi educada num código de sexualidade ainda muito rígido - que dita o que é próprio ou impróprio; o que é "natural", agradável, "normal", ou, ao contrário, danoso, excessivo; aquilo que é passível de admiração, aceitação ou, de repulsa, negação (Botacci, 2011). Portanto, são diversos os sentidos subjetivos produzidos sobre a sexualidade, podendo ser atravessados por histórias de vidas marcadas pelo fatalismo e pela repressão de desejos e afetos.

As pesquisas sobre a sexualidade da pessoa idosa geralmente ressaltam a perspectiva biológica (Bernardo \& Cortina, 2012; Ribeiro, 2009; Souza, 2009), a prevenção de infecções sexualmente transmissíveis (IST), com destaque para a incidência da contaminação pelo vírus da imunodeficiência humana (HIV) (Arrais, Rufino, Santos, \& Chaves, 2014; Garcia, Lima, Silva, Andrade, \& Abrão, 2012; Laroque, Affeldt, Cardoso, Souza, Santana, \& Lange, 2011; Lazzarotto, Deresz, \& Sprinz, 2010; Mochio, Balbino, \& Karlinke, 2011; Saldanha, Felix, \& Araújo, 2008; Souza, 2008).

No Amazonas, há predominância de mulheres idosas. "Esse contingente feminino é mais expressivo quanto mais idoso for o segmento" (Costa \& Schor, 2014 , p. 8). Isso leva à constatação de que o mundo de muitos idosos é um mundo das mulheres. O que torna relevante compreender as contingências de vida das idosas.

Desse modo, há a necessidade de investimentos para a produção de conhecimentos sobre a sexualidade das idosas, que enfatize os aspectos psicossociais, especialmente num contexto em que os preconceitos produzem estigmas e marginalizam a sexualidade na terceira idade, sendo "percebida como um ciclo da vida do "não sentir", do "não desejo", do "não querer", entre outros rótulos que a sociedade costuma enfatizar", produzindo uma identidade social assexuada (Risman, 2005, p. 01).

Diante dessas premissas, para a compreensão dos resultados desta pesquisa, foram aplicados conceitos da psicologia sócio-histórica. A esta área do conhecimento concerne reconhecer as experiências humanas no campo da construção subjetiva da vivência do sujeito como suscetível de novas possibilidades. Para isso, adotou-se a articulação com a categoria de análise chamada "sentido". Esta, por sua vez, "referese à dimensão subjetiva da palavra para cada indivíduo, composto por relações que dizem respeito ao contexto de uso da palavra e as vivências afetivas do indivíduo" (Severino, 1998, p. 50).

Espera-se que este estudo contribua para o rompimento do fatalismo entre os discursos dos idosos que preferem anular-se, por acreditarem que, por estarem idosos, não podem mais gozar de todos os aspectos da vida.

A construção identitária da mulher amazonense foi influencia pelos diferentes projetos políticos de ocupação da Amazônia. Marangoni, Diniz, Neves, Pontes e Martins (2017), ao analisarem a condição feminina na Amazônia, afirmam que do período colonial aos dias atuais podem ser identificadas diferentes formas de objetificação da mulher. No período colonial, por motivos políticos e econômicos, a liberdade sexual foi estimulada, os corpos das mulheres foram utilizados como instrumento de dominação.

No auge da borracha, o prazer e a diversão eram permitidos somente aos homens. Os seringais eram locais para homens. Tolerava-se a prostituição, "mas às prostitutas eram direcionadas todas as formas de punição e práticas coercitivas" (Mangoni, 2017, p. 26). Com o declínio da borracha e a decadência da economia, Manaus entrou em colapso. Somente nos anos 60 teve um movimento de revigoramento, com a implantação da Zona Franca de Manaus e, posteriormente, do Pólo Industrial de Manaus (PIM).

A visão colonialista que prevaleceu no PIM caracteriza-se por uma política sexista que perpetua o controle do corpo da mulher, pois para ser contratada tinha que apresentar teste de gravidez, não poderia ter filhos, nem ser casada, exigências que somente foram extintas após movimentos de resistência das mulheres. No entanto, permanece até os dias atuais o uso e o controle do corpo da mulher no chão da fábrica.

Considerando que a sexualidade foi inserida historicamente em um sistema de controle com interditos e proibições subordinadas a uma moral que o saber-poder, posteriormente, reiterou sob a 
forma de normas médicas, que as relações de gênero socialmente construídas produziram silenciamentos e invisibilização das mulheres em diversas instituições e nas relações afetivas e sociais, que existem diferentes construções de mitos e "verdades" em torno da sexualidade da pessoa idosa, este estudo teve como objetivo compreender os sentidos de sexualidade construídos por mulheres idosas.

\section{Método}

Este estudo faz parte de uma pesquisa mais ampla, realizada em Manaus, Amazonas. A metodologia adotada lança mão da história de vida, para oportunizar uma relação dialógica entre pesquisadores e participantes. Privilegia-se a linguagem como categoria importante na construção do sujeito. Vigotski (1934/2003) considera que a palavra funciona como uma zona fluida, e concebida como um acontecimento semântico particular, constituído nas relações sociais, em que uma gama de signos é posta em jogo, permitindo a emergência de processos de singularização em uma trama interacional histórica e culturalmente situada. A pesquisa de campo tem abordagem qualitativa de caráter descritivo-exploratório.

\section{Participantes}

Participaram cinco mulheres idosas vinculadas ao grupo "Oficinas de Memória", que ocorre na Policlínica de Atenção à Melhor Idade, situada na zona centro-sul de Manaus. A faixa-etária das participantes situa-se- entre 60 e 68 anos. Grande parte dessas idosas nasceu na área rural do estado do Amazonas, deslocando-se para a capital na adolescência, em busca de melhores oportunidades e condições de vida.

Para preservar-lhes o anonimato, as participantes foram identificadas pela letra "I", que indica "idosa", acompanhada do número de ordem de realização das entrevistas.

Em relação ao estado civil, duas são casadas (I2 e I5), uma é solteira (I3), uma é separada (I1) e há uma viúva (I4). As idosas casaram-se entre 13 e 21 anos. As casadas convivem ou conviveram com seus cônjuges por mais de 30 anos, tendo suas primeiras experiências sexuais após o casamento e com os maridos. As idosas tiveram o primeiro filho ainda na adolescência, entre 14 e 17 anos, o que concorreu para que o número deles variasse entre 5 e 14 filhos.

Quanto ao grau de escolaridade, duas das entrevistadas não concluíram o ensino "primário" da época, duas cursaram ou concluíram o Nível Fundamental de Ensino, e apenas uma completou o
Segundo Grau de Ensino, hoje Ensino Médio.

A renda mensal das idosas variou em torno de um a três salários mínimos. Em alguns casos, essa renda era composta pela aposentadoria do ex-marido, bolsas do Governo Federal ou, até mesmo, por uma renda extra, proveniente da venda de artesanato e de catálogos.

\section{Instrumento}

$\mathrm{O}$ instrumento de coleta de dados utilizado foi a entrevista semiestruturada. O discurso das idosas é visto como um processo, não como objeto, pois, segundo Vigotski (1934/2003), a palavra é dinâmica e apresenta uma multiplicidade de significados pelo fato de estar inserida em um contexto sócio-historicamente construído. Sendo assim, os pesquisadores seguiram a proposta de Ozella (2009), segundo a qual, durante a entrevista, é necessário buscar temas/conteúdos/ questões centrais apresentados pelo sujeito, entendidos menos pela frequência e mais por serem aqueles que motivam, geram envolvimento.

\section{Procedimentos}

A pesquisa obteve a aprovação do Comitê de Ética da Universidade Federal do Amazonas sob o número de protocolo 394.085. Foi utilizado o Termo de Consentimento Livre e Esclarecido assinado pelos sujeitos pesquisados, além das autorizações institucionais pertinentes a cada campo de pesquisa.

Os participantes foram entrevistados individualmente, após a Oficina da Memória, no período de outubro a novembro de 2013. Todas as entrevistas foram realizadas na sala da psicóloga. $\mathrm{O}$ primeiro contato com as idosas foi intermediado pela diretora. Nesse momento, foram explicados os objetivos do trabalho e esclareceu-se como seriam realizadas as entrevistas.

\section{Análise dos dados}

Os dados foram analisados com base na proposta teórico-metodológica de Vigotski, apontada por Aguiar e Ozella $(2006,2013)$, relativa à constituição dos Núcleos de Significação como instrumentos para a apreensão dos sentidos. Seguiram-se os seguintes procedimentos: "pré-indicadores" - leitura flutuante na busca de temas livres; "indicadores" - processo de aglutinação dos pré-indicadores pela similaridade ou pela contraposição; e "construção e análise dos núcleos de significação" - formação de categorias que emergiram do empírico para o interpretativo. Nessa proposta de análise, propõe-se que a nomeação 
dos núcleos pode ser extraída da própria fala dos sujeitos, em uma ou mais expressões que favoreçam a articulação entre os núcleos formados e os sentidos dos participantes, numa proposta construtiva/interpretativa de análise.

\section{Resultados e discussão}

Levou-se em consideração a influência dos processos de construção social na produção de sentidos, com base na história de vida das participantes da pesquisa. Elas atribuíram sentido às experiências sexuais e às ideologias capitalistas sobre a pessoa idosa vinculadas à improdutividade. Também fizeram interlocuções com aspectos mais amplos da sexualidade abordados pela Organização Mundial de Saúde (OMS, 2000) e outros discursos que proporcionaram ideias emancipatórias frente à experiência subjetiva de sua sexualidade.

A seguir, são apresentados os resultados da pesquisa construídos em três núcleos de significação para apreensão de sentidos das mulheres participantes desta pesquisa: Ato sexual: sexo como obrigação, já estamos enjoadas, já queremos é sossego!, Eu não tenho mais aquela vontade: a culpa é da doença; Eu estou com muita vontade de fazer sexo: eu ainda gosto!

\section{Ato sexual: sexo como obrigação, já estamos enjoadas, já queremos é sossego!}

Os discursos analisados apresentam produções de sentidos sobre sexualidade, atravessados pela construção sócio-histórica das categorias "Mulher" e "Idosa". Os discursos revelaram marcas das relações de gênero e do paradigma mecanicista que permeia a ideologia capitalista, que considera os idosos improdutivos. Entende-se que esses sentidos podem interferir e legitimar a forma de uma pessoa comportarse e o que ela deve negar em si para enquadrar-se nos modelos socialmente construídos, conforme pode ser constatado nos resultados apresentados a seguir.

Os discursos das mulheres idosas indicam que a lógica patriarcal outorgou ao homem o poder de tornar-se o detentor do corpo feminino. Na lógica patriarcal, a mulher ocupava uma posição de submissão e subordinação na sociedade mediante o argumento da fragilidade física e, portanto instituiuse que sua natureza era inferior ao do homem (Silva, 2009). Nesse sentido, Barreto (2004, p. 64) caracteriza o patriarcalismo como "uma autoridade imposta institucionalmente, do homem sobre mulheres e filhos no ambiente familiar, permeando toda organização da sociedade, da produção e do consumo, da política, à legislação e à cultura". No contexto desta pesquisa, isso pode ter refletido num desejo sexual disciplinado e negado às mulheres participantes deste estudo, além de demonstrar o quanto a construção social de um paradigma mecanicista acerca da pessoa idosa implicou na elaboração da autoimagem com "prazo de validade" em torno da sua sexualidade.

Embora tenha ocorrido, nas últimas décadas, o franco declínio do paradigma patriarcal, ele orientou inúmeras gerações de mulheres, que hoje se apresentam com mais idade, submetendo-as ao disciplinamento, à repressão sexual e social, limitando-as quanto à escolaridade, com restrições ao seu corpo e à sua sexualidade, ao acesso e permanência ao mercado de trabalho, marcadas pela aparente negação de interesse e capacidade para a política. Tais aspecto contribuíram para que essas mulheres, já idosas, tivessem diferentes trajetórias e experiências de vida (Motta, 2011), conforme desvelou-se nesta pesquisa.

Essas perspectivas gerais fundamentam-se em dois aspectos dos discursos que fizeram emergir os sentidos deste núcleo de análise: a "obrigação" e o esgotamento da sexualidade dessas mulheres. Elas entendem a sexualidade como um atributo pertencente a outras fases da vida e a percebem como obrigação entre elas. Têm-se a ideia de que, na velhice, a sexualidade se esgota, como pode ser visto nas falas a seguir:

Eu nem tenho mais vontade. E, eu já fiz tanto que enjoei ... Assim, idoso como nós, já estamos enjoadas, já queremos é sossego!.. Graças a Deus, estamos vivendo como dois irmãos dentro de casa. Eu já dei foi Graças a Deus, porque meu marido fracassou, coitado! Eu acho assim, que a pessoa que tem seu par direito, seu companheiro, ela tem obrigação de fazer. (I2)

Eu sou uma pessoa que nunca fui exagerada em sexo, não sei por quê... E hoje, agora, com essa idade, e ele também, né? Está quase acabado. (I5)

Esses discursos permitem-nos avaliar a qualidade das experiências sexuais dessas mulheres com base nos sentidos por elas produzidos, pois o sentido subjetivo, para González Rey (2003), é a construção subjetiva do sujeito com a sua ação. De acordo com Vigotski (1934/2003), o sentido seria uma vivência atual do sujeito, considerado como uma das forças essenciais do desenvolvimento humano. O sentido expressado por essas mulheres torna-se pista para a compreensão da existência de uma história marcada pela obrigação de fazer sexo. Além disso, a possível disfunção sexual do marido converte-se numa forma de libertação dessa obrigação. 
Os discursos atribuem um aspecto negativo ao ato sexual, que invisibiliza outras possibilidades saudáveis que a prática sexual pode proporcionar na fase de desenvolvimento que atualmente vivenciam. Nessa acepção, Vieira (2012) considera que a idade não retira a sexualidade do ser humano. Assim, os idosos não precisam negar a sua sexualidade em razão de preconceitos e tabus e devem vivenciar a sexualidade nessa etapa de suas vidas.

Discute-se ainda, a despeito dos sentidos de "obrigação" e "do fim da sexualidade da pessoa idosa", a reflexão de Miranda e Banhato (2008), ao apontarem que a forma como a pessoa vivenciou o sexo ao longo da vida também influencia como ele será experimentado na velhice. Esses autores consideram que um indivíduo, cuja sexualidade foi silenciada e não teve uma vida sexual feliz na fase adulta e tampouco possui informação correta sobre o tema, poderá encontrar muitas barreiras que dificultem a expressão de sua sexualidade na velhice. O sentido de obrigação expressado por essas mulheres pode ter sido construído por experiências sexuais voltadas para servir ao outro ou pela obrigação da manutenção do casamento.

No que se refere ao esgotamento da sexualidade, Vieira (2012) assinala que, muitas vezes, a pessoa absorve o estereótipo da idosa incapaz e improdutiva. Tais questões coadunam-se sócio-historicamente com o contexto da Revolução Industrial, no século XVIII, quando a figura da pessoa idosa passou a ser sinônimo de decadência e de inutilidade. Perante a sociedade capitalista, muitas vezes, idosas vivem numa situação marginal, tendo em vista suas limitações físicas e psicológicas e o consequente desprezo do ser humano por sua inaptidão ao trabalho e ao capital (Colares \& Saraiva, 2016).

Nesse aspecto, muitos estudos afirmam que a sexualidade não se esgota neste ciclo de vida. Não é a idade que determina a ausência do desejo ou de relações sexuais. A sexualidade da pessoa idosa pode assumir caminhos distintos em que o desejo, que não morre, encontra múltiplas maneiras de manifestarse. A sexualidade da idosa precisa ser compreendida de forma complexa e para além dos estereótipos difundidos na cultura capitalista sobre "o velho improdutivo" e "assexuado" (Debert \& Brigeiro, 2012; Mucida, 2004).

No caso em estudo, fica claro que os estereótipos sociais e a pressão que exercem podem ter influenciado para que essas mulheres não pudessem manifestar livremente sua sexualidade. Seja pelo contundente negativismo cultural, no que diz respeito ao sexo na velhice, seja no reflexo de uma simples atitude de rejeição pelo fato de ser idoso, o indivíduo acaba tomando para si o estereotipo cultural negativo da pessoa idosa como um inválido assexuado, conforme pontua Oliveira (2009). Frente à lógica neoliberal, compreende-se que a ideia do "inválido" vinculase à significação do inválido-produtivo com a do "estar quase acabando". Isto é, do esgotamento da sexualidade.

Desse modo, esses sentidos estão articulados com os significados produzidos em uma sociedade machista e sexista. A sociedade produz estereótipos culturais, orientando e legitimando a responsabilidade das mulheres limitada à educação dos filhos, aos cuidados das tarefas domésticas. Quanto ao sexismo, trata-se de uma forma de discriminação que conduz à subalternização, à marginalização ou mesmo à exclusão de pessoas ou grupos com base no seu sexo - norteiam as relações afetivas e sexuais, submetendo as mulheres a uma posição degradante em seus relacionamentos e na sua sexualidade (Saffioti, 2004).

Conforme González Rey (2003), o sujeito constrói-se com base em sua experiência única, na qual ele se constitui e é constituído em um processo dialético que está em constante desenvolvimento. Entende-se, nessa perspectiva, que os sentidos dessas mulheres articularam-se frente aos pactos de subserviência nessas relações que resultaram na construção de um sentido de sexualidade como ato sexual obrigatório, fornecendo ao marido, de modo sutil, a dominação e a regulação até no momento de sentir prazer. Além disso, fica claro o conformismo frente às ideologias mecanicistas e capitalistas impostas de que há uma estagnação da pessoa idosa, no caso desses discursos, a ideia de que a sexualidade esgota-se na velhice. Conforme Farias e Cassab (2015), a divisão sexual do capitalismo disciplina as mulheres a um comportamento diferente, pautado em uma educação repressora, enquanto os homens são conduzidos à liberdade, como se a moralidade vigente devesse ser cumprida apenas pelas mulheres.

\section{Eu não tenho mais aquela vontade: a culpa é da doença}

Outro sentido de sexualidade produzido pelas mulheres desta pesquisa encontra-se relacionado aos agravos diretos ou indiretos à saúde. Evidencia-se que há a prática sexual. Entretanto, as mulheres que participaram da pesquisa não revelaram outras formas de satisfação sexual, além da penetração, conforme demonstrado por I1 e I5.

Não sei se tem a ver com a minha operação, que fez perder tudo isso, não sei. Eu sei que eu não tenho 
mais aquela vontade, aquela alegria, aquele prazer de chegar naquele orgasmo bom! (I1)

Eu me considero sexualmente ativa, mas já tem o problema dele. Porque eu não sei se é devido ele fumar muito ou se é porque ele tem pressão alta. Ele é hipertenso, então ele não tem mais condições, não. Às vezes ele até que ainda tenta, coitado! Mas isso é de 15 em 15 dias. (I5)

Esse sentido expressado por essas mulheres pode legitimar a anulação e a retirada da possibilidade de sentir prazer na terceira idade. Embora o desejo sexual esteja presente, essas idosas não apontam outras estratégias para receber e dar prazer na relação com seu parceiro, como evidencia o discurso de I5. Esse resultado coaduna-se com o que diz Machado (2014, p. 12), ao considerar que "o foco principal da relação não é somente o ato sexual em si (penetração), mas a oportunidade de expressar admiração e afeto, aliados à confirmação de um corpo funcional e o prazer de tocar e ser tocado".

Os discursos também mostram que elas associam, tanto à cirurgia quanto ao parceiro, a responsabilidade de vivenciar o prazer. Atribuem, portanto, o sentido de sexualidade a um corpo saudável. E nesse corpo, que não se encontra mais "normal" em razão de alguma patologia, a sexualidade vira uma "anomalia". Assim, considera-se uma ideia "normatizada" frente a um corpo que "não pode" expressar a sexualidade. Lançase mão da ideia de que "o normal não é uma média correlativa a um conceito social, não é um julgamento de realidade, é um julgamento de valor, é uma noçãolimite que define o máximo de capacidade psíquica de um ser. Não há limite superior da normalidade" (Canguilhem, 1943, p. 80).

As condutas dessas mulheres podem acarretar prejuízos ao desenvolvimento sexual e afetivo, por invisibilizar as múltiplas formas e as novas dimensões da vida frente à sua sexualidade. Ao considerar as múltiplas formas de expressão da sexualidade e não apenas a penetração, Santos e Carlos (2003) sugerem que o cuidado e a intimidade exercem uma função de complementação muito satisfatória do prazer na velhice.

Ainda considerando o sentido de "culpa a doença", a ausência da autonomia sobre a própria sexualidade e suas manifestações de desejo, entende-se que as mulheres participantes desta pesquisa são frutos de uma visão transmitida pela criação anterior à década de 1950. Nesse momento, as ideias eram fortemente marcadas por uma conjuntura em que as famílias absorveram as ideologias de que o lugar da mulher era no lar, de que trabalhar fora as masculinizava, e de que o marido teria que ser o provedor da família (Santos \& Diniz, 2011).

No tocante a esta questão, Vigotski (1931/2007) compreende que o desenvolvimento psicológico das pessoas é parte do desenvolvimento histórico geral da espécie humana e assim deve ser entendido. Portanto, a análise aponta o fato de essas mulheres terem sido educadas dentro de um padrão de valores sociais e influências culturais sexistas correntes nas comunidades amazônicas e que legitimaram e disciplinaram um jeito de ser mulher.

Ao falar da identidade da mulher e das influências culturais normatizadoras de um padrão feminino, Cerqueira (2013) ressalta que pode ter trazido consequências para a vida sentimental e sexual feminina, uma vez que a mulher não era tão estimulada a se ver, a se tocar e a se conhecer sexualmente, quando comparada ao homem. Educava-se, nesse sentido, para não permitir que a sexualidade feminina viesse à tona.

A sexualidade silenciada pela doença pode ter sido uma posição mais assertiva encontrada por essas mulheres que experimentaram, em seus percursos de vida, a imposição de um "padrão de mulher ideal", "recatada e do lar", no qual ter voz para manifestar outras formas de experiências da sexualidade poderia ser visto como transgressão.

\section{Eu estou com muita vontade de fazer sexo: eu ainda gosto!}

Esta categoria foi construída com base no desejo de ainda querer fazer sexo. Os discursos revelaram que essas idosas construíram sentidos que subvertem o paradigma de que o idoso é "improdutivo sexualmente". Compreende-se, portanto, que essas mulheres alteraram as relações de subordinação e opressão, produzidas tanto pelas relações de gênero quanto pelo capitalismo, que significaram crenças ocidentais da ausência do apetite sexual na velhice, como se observa nos discursos de I3 e I4.

Toda vez pintava 'um maninha', eu ia às festinhas,
sempre tinha um paquera, mas era uma coisa que me
satisfazia bem, gostava, eu gostava... E se hoje eu
encontrar alguém, eu ainda gosto! (I3)

Eu estou com muita vontade de fazer sexo, mas doutora, eu não tenho marido! (I4)

Esses discursos rompem com o paradigma construído desde a Idade Média, de que a pessoa idosa esgota a sua sexualidade, como ressalta Oliveira (2009), ao afirmar que essas crenças ocidentais 
propagam que o apetite sexual extingue-se com a chegada do envelhecimento.

De acordo com os discursos, há mulheres idosas, como é o caso de I3 e I4, que podem experimentar a velhice com sua sexualidade fortalecida, atribuindo um sentido positivo sobre a sexualidade. Nesse aspecto, Guzzo e Lacerda (2007) consideram que o fortalecimento é melhorado quando as pessoas tomam consciência individual e/ou coletiva do seu entorno. Desse modo, mudam positivamente suas trajetórias de vida, tornando-se protagonistas de suas histórias, o que traz implicações positivas para seu desenvolvimento psicossocial.

Fica evidente, portanto, que os sentidos de I3 e I4 desmascaram verdades pré-estabelecidas e construídas em torno da sexualidade da mulher e das pessoas idosas. É importante ressaltar que seus discursos não mostram uma postura conformista, baseada em noções indubitáveis e óbvias pela regulação e pelo controle da sexualidade, em conformidade com a maioria dos mitos e preconceitos a respeito da sexualidade do idoso que se costuma pregar. Por fim, elas romperam a postura conformista e passiva ao reafirmar: "eu estou com muita vontade de fazer sexo" e "se hoje eu encontrar alguém, eu ainda gosto!". Essa ruptura ocorre, de acordo com o que Martín Baró (1998) e Ambrosini (2012) afirmam, com a emancipação. Consoante esses autores, é por meio do esclarecimento que se permite a formação de um sujeito autônomo, consciente dos seus desejos, crítico e livre, como é o caso dessas idosas. Ao subverterem o paradigma social de que na velhice a sexualidade se esgota, elas rompem com o silenciamento de sua sexualidade.

O fortalecimento constatado no discurso de I4 pode ser verificado no fragmento a seguir, como uma possibilidade de mudança positiva na história de vida dessa mulher, ao evidenciar um sentido relacionado à paixão. Neste aspecto, desvela-se que esse sentimento, expresso no sentido subjetivo de I4, não deve ser legitimado por faixa etária. Isto é, a paixão não se restringe ao período que é compreendido pela juventude. Esses sentimentos podem ser vividos em todas as etapas de vida de uma pessoa. Ressalta-se que a juventude é aqui entendida, no campo semântico da diversidade, como o modo que a idosa vivencia esse período.

Fui vivendo a minha vida, sem me interessar por ninguém. Mas quando foi esse ano, eu conheci um senhor e me interessei bastante por ele. E ele me deixou assim com o meu coração bem mexido. Então aquilo me mexeu muito, porque a gente vive só, a gente vive carente, e eu muito carente tinha acabado de fazer a cirurgia do meu olho, e ficava muito sozinha e aquilo mexeu muito comigo. (I4)

O discurso revela que a idosa, embora tenha vivenciado seu percurso de vida sem se vincular a alguém, na velhice foi possível despertar a necessidade dessa vivência. Essa necessidade veio à tona com a experiência de sentimentos de estar sozinha e de carência que, aliada ao procedimento cirúrgico, fortaleceu ainda mais a necessidade de se unir a alguém.

Esse discurso possibilita o questionamento das ideologias sexuais socialmente impostas, que acabaram limitando essas idosas a permitirem-se experiências como as vividas por I4. As construções sociais, numa visão histórico-cultural, evidenciam que essas mulheres, hoje estereotipadas como "velhas assanhadas, viúvas-alegres", muitas vezes foram oprimidas pelos valores sociais ou por um marido, mas, ao conhecer um novo parceiro, reinventam-se e usufruem de situações antes nunca vivenciadas. Contudo, muitas são as práticas limitantes e opressoras à sexualidade da mulher idosa, nas quais é dito a elas que não podem amar e, portanto, a sexualidade da pessoa idosa é vista como um tabu (Almeida \& Lourenço, 2007).

De acordo com Vigotski (1934/2003), na perspectiva sócio-histórica, a sexualidade da pessoa idosa pode ser compreendida como um processo transitório, marcado por contradições, imerso em uma história e em uma cultura nas quais são gerados sentidos e significados próprios. Para o mesmo autor, a pessoa é influenciada pelo meio, mas também modifica o entorno da cultura em que está inserida, de acordo com sua história, demonstrando a sua singularidade em suas expressões e em suas atitudes perante os acontecimentos durante a vida.

Em resumo, I3 e I4 são protagonistas de uma construção que legitima a aceitação de uma vida sexual ativa na terceira idade, entendimento muito recente, já que a história da sexualidade do idoso ainda é bastante invisibilizada, podendo ser considerada como imoral ou algo extremamente absurdo. Os discursos facultaram também a reflexão sobre as dificuldades afetivo-sexuais que mulheres com mais idade vivenciam, pelo fato de estarem sozinhas, viúvas, divorciadas ou solteiras.

\section{Considerações finais}

Este artigo teve como objetivo compreender os sentidos de sexualidade construídos por mulheres 
idosas. Conclui-se, com base nos resultados, que os sentidos de sexualidade construídos pelas idosas participantes do estudo desenvolvido evidenciam um claro direcionamento em dois grupos: as mulheres que "não têm mais vontade de fazer sexo" e as que ainda referem fazê-lo.

Os sentidos de sexualidade atribuídos por essas mulheres - sexo como obrigação e a sexualidade vinculada ao corpo saudável para viver a sexualidade, culpando a doença - podem estar pautados em relações socialmente construídas pelos modelos de gênero, implicando diretamente no desejo sexual e em ideologias mecanicistas produzidas pelo sistema capitalista seguindo a ideia de "corpo improdutivo".

Outro aspecto importante a considerar é que, mesmo idosas que evocam ainda sentir desejo sexual não se permitem vivenciar novas experiências. Elas consideram que não possuem marido ou que é preciso estabelecer vínculos afetivos correlacionados a sentimentos, como carinho, companheirismo e amizade, não se limitando a sexualidade ao ato sexual. As relações de curto prazo ou com parceiros mais jovens ainda não são percebidas por essas mulheres como um aspecto possível.

Sugere-se que a psicologia tenha um olhar pormenorizado acerca da sexualidade do idoso, e que a psicóloga, ao se inserir em instituições que trabalham com idosas, como a que foi estudada, possa ter uma escuta sensível e, ao perceber idosas com demandas semelhantes às evidenciadas neste estudo, busquem discutir temáticas, como namoro, sexo e masturbação - principalmente no contexto das mulheres, que têm historicamente sua sexualidade reprimida e silenciada.

Torna-se necessário que a psicóloga que atua com idosos trabalhe a temática sexualidade numa perspectiva crítica, para que sua atuação vá além dos aspectos biológicos ou das categorias estruturadas sugeridas pelos tradicionais manuais de psicologia do desenvolvimento humano. Para isso, sugerem-se as oficinas de gênero e sexualidade e de educação em saúde, para promover a participação dialógica do idoso, com vistas à tomada de consciência, bem como à construção de sua autonomia e emancipação da liberdade sexual. A atuação como psicólogo requer subsídios políticos e transformadores para serem mediadores dessas discussões com variados tipos de população, em diversos tipos de estágios de desenvolvimento. As rodas de conversas com escuta qualificada entre os idosos podem ser um momento para trocas dialógicas diante dos anseios, dúvidas, curiosidades e angústia que envolvem a questão da sexualidade.
Tendo em vista a complexidade do tema estudado, sugere-se a continuidade das pesquisas para que se possa aprofundar o conhecimento sobre a questão e contribuir de forma mais significativa para o conhecimento do assunto, de modo a tornar a escuta do psicólogo cada vez mais sensível.

\section{Referências}

Aguiar, W. M. J \& Ozella, S. (2006). Núcleos de Significação como Instrumento para a Apreensão da Constituição dos Sentidos. Revista Psicologia Ciência e Profissão, 26(222245). Recuperado de http://dx.doi.org/10.1590/S1414$\underline{98932006000200006}$

Aguiar, W. M. J \& Ozella, S. (2013). Apreensão dos sentidos: aprimorando a proposta dos núcleos de significação. $R$. bras. Est. pedag., 94(236), 299-322. Recuperado de http://www. scielo.br/pdf/rbeped/v94n236/15.pdf

Almeida, T. \& Lourenço, M. L. (2007). Envelhecimento, amor e sexualidade: utopia ou realidade. Rev. Bras. Geriatr. Gerontol., 10(1), 101-113. Recuperado de http://www. redalyc.org/pdf/4038/403838772008.pdf

Ambrosini, T. (2012). Educação e emancipação humana: uma fundamentação filosófica. Thaumazein, 5(09), 40-56. Recuperado de http://www.periodicos.unifra.br/index.php/ thaumazein/article/view/85/pdf

Arrais, A. R., Rufino, M., Santos, F. L. S., \& Chaves, P. R. S. (2014). Atividade sexual e HIV/AIDS na terceira idade: a vivência de alunos da Universidade da Maturidade da Universidade Federal do Tocantins. Brasiliamedica, 51, 4-12.

Barreto, M. P. S. L. (2004). Patriarcalismo e o feminismo: uma retrospectiva histórica. Revista Ártemis, 1, 64-73. Recuperado de http://www.periodicos.ufpb.br/ojs/index. php/artemis/article/view/2363/2095

Bernardo, R. \& Cortina, I. (2012). Sexualidade na Terceira Idade. Rev. Enferm., 13(1), 74-78. Recuperado de http:// www.unisa.br/graduacao/biologicas/enfer/revista/ arquivos/2012-1-13.pdf

Botacci, L. F. G. (2011). A construção social do sexo: alguns aspectos a considerar sobre a terceira idade. Revista Trilhas da História, 1(1), 145-158. Recuperado de http:// trilhasdahistoria.ufms.br/edicao1/ensaio2.html

Cerqueira, A. T. A. (2013). Sexualidade no idoso. UOL comportamento. Recuperado de http://mulher.uol.com.br/ comportamento/noticias/redacao/2013/05/03/vida-sexualnao-para-na-velhice-mas-e-preciso-superar-obstaculos.htm

Colares, A. F. V \& Saraiva, L. S. S. (2016). Problematizando o "Velho" e o "Idoso" sob a Ótica do Capital. Revista NAU Social, 7(12), 55-67.

Costa, E. A. C. \& Schor, T. (2014). Envelhecimento populacional e sua produção histórica no Brasil, Amazonas, Tefé, Alvarães e Uarini-AM. In Associação dos Geógrafos Brasileiros (Org), Anais do VII Congresso Brasileiro de Geógrafos. Vitória, ES: AGB. Recuperado de http:// www.cbg2014.agb.org.br/resources/anais/1/1404152885 ARQUIVO ENVELHECIMENTOPOPULACIONALE SUAPRODŪCAOHISTORICANOBRASIL_ArtigoCompleto. pdf

Debert, G. G. \& Brigadeiro, M. (2012). Fronteiras de gêneros e a sexualidade na velhice. Revista Brasileira de Ciências Sociais, 17(80), 37-54. 
Farias, E. A. \& Cassab, L. A. (2015). As expressões do patriarcalismo na experiência de mulheres idosas [Resumo]. In Associação dos Pós-graduandos em História (Org.), Anais do VII Congresso Internacional de História (pp. 34543455). UNESPAR, Apucarana, PR: APGH.

Garcia, G. S., Lima, L. F., Silva, J. B., Andrade, L. D. F., \& Abrão, F. M. S. (2012). Vulnerabilidade dos Idosos frente ao HIV/Aids: Tendências da Produção Científica Atual no Brasil. DST. J bras Doenças Sex Transm., 24(3), 83-188.

Gonzalez Rey, L. F. (2003). Sujeito e subjetividade: Uma aproximação sócio-histórica (R. S. L. Guzzo, Trad.). São Paulo: Thomson.

Gradim, C. V. C, Souza, A. M. M., \& Lobo, J. M. (2007). A prática sexual e o envelhecimento. Cogitare Enferm., 12(2), 2004-2013.

Guzzo, R. S. L \& Lacerda, J. R. F. (2007). Fortalecimento em tempo de sofrimento: reflexões sobre o trabalho do psicólogo e a realidade brasileira. Revista Interamericana de Psicologia, 41(2), 231-240.

Laroque, M. F., Affeldt, A. B., Cardoso, D. H., Souza, G. L., Santana, M. G., \& Lange, C. (2011). Sexualidade do idoso: comportamento para a prevenção de DST/AIDS. Revista Gaúcha de Enfermagem, 32(4), 774-780. Recuperado de https://dx.doi.org/10.1590/S1983-14472011000400019

Lazzarotto, A. R., Deresz, L. F., \& Sprinz, E. (2010). HIV/ AIDS e Treinamento Concorrente: a Revisão Sistemática. Revista Brasileira de Medicina do Esporte, 16(2), 149-154. Recuperado de http://www.scielo.br/scielo.php?script=sci arttext\&pid=S1517-86922010000200015\&lng=en\&tlng $=\mathrm{pt}$

Marangoni, V. L., Diniz, G. R. S., Neves, A. L. M., Pontes, M. T. C. M, \& Martins, G. C. (2017). Panorama das condições femininas no Amazonas: do período colonial ao século XX. Interfaces Científicas - Humanas e Sociais, 6(1), 21-32.

Martín-Baró, I. (1998). Psicología de la liberación. Madrid: Editorial Trotta.

Maschio, M., Balbino, A. P., De Souza, P. F., \& Kalinke, L. (2011). Sexualidade na terceira idade: medidas de prevenção para doenças sexualmente transmissíveis e AIDS. Rev Gaúcha Enfermagem, 32(3), 583-589. Recuperado de http:// www.scielo.br/scielo.php?script=sci arttext\&pid=S1983$14472011000300021 \& \operatorname{lng}=$ en\&tlng $=$ pt.

Miranda, L. \& Banhato, E. (2008). Qualidade de vida na terceira idade: a influência da participação em grupos. Psicologia em Pesquisa, 2(01), 69-80. Recuperado de http://www.ufjf.br/ psicologiaempesquisa/files/2009/11/v2n1008.pdf

Motta, A. B. (2011). As velhas também. Ex aequo, 23, 13-21. Recuperado de http://www.scielo.mec. pt/scielo.php?script=sci_arttext\&pid=S0874-

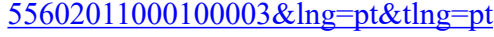

Mucida, Â. (2006). O Sujeito não envelhece: psicanálise e velhice. Rio de Janeiro:Autêntica.

Oliveira, J. S. C. (2009). O viver com Aids depois dos 50 anos e sua relação com a qualidade de vida. Dissertação de Mestrado, Programa de Pós-graduação em Psicologia Social, Universidade Federal da Paraíba, João Pessoa.

Organização Mundial de Saúde [OMS]. (2000). Boletim informativo DST/AIDS. Diretoria de epidemiologia e vigilância Sanitária; Diretoria executiva de epidemiologia, programa estadual DST/Aids. Secretaria de Saúde - PE. Jan/ Abr. Ano II, 1.

Ozella, S. (2009). Pesquisar ou Construir Conhecimento. O Ensino da Pesquisa na Abordagem Socio-histórica. In A. M.
B. Bock (Org.), A Perspectiva Sócio-histórica na Formação em Psicologia (4a ed., pp. 113-131). Petrópolis, RJ: Vozes.

Ribeiro, A. (2009). Sexualidade na Terceira Idade. In M. Papaleo \& Cols. (Orgs.), Gerontologia. A velhice e o envelhecimento em visão globalizada (pp. 3-12). São Paulo, Athenen.

Risman, A. (2005) Sexualidade e terceira idade: uma visão histórico-cultural.Textos Envelhecimento,08(1). Recuperado de $\quad$ http://revista.unati.uerj.br/scielo.php?script $=$ sci arttext\&pid=S1517-59282005000100006\&lng=pt\&nrm=iso

Saffioti, H. (2004). Gênero, patriarcado e violência. São Paulo: Fundação Perseu Abramo.

Saldanha, A. A. W., Felix, S. M. F., \& Araújo, L. F. (2008). Representações sobre a Aids na velhice por coordenadoras de grupos da terceira idade. Psico-USF, 13(1), 95-103.

Santos, L. S. \& Diniz, G. R. S. (2011). Donas de casa: classes diferentes, experiências desiguais. Psicologia Clínica, 23(2), 137-149. Recuperado de https://dx.doi.org/10.1590/S0103$\underline{56652011000200009}$

Santos, S. S. \& Carlos, S. A. (2003). Sexualidade e amor na velhice. Estudos Interdisciplinares de Envelhecimento, 5(1), 57-80.

Severino, A. J. (1998). Produção de conhecimento, ensino/ aprendizagem e educação. Interface - Comunicação, Saúde, Educação, 2(3), 11-20. Recuperado de http:// www.scielo.br/scielo.php?script $=$ sci_arttext\&pid $=\mathrm{S} 1414$ $\underline{32831998000200002 \& \operatorname{lng}=\text { en\&tlng }=p t}$

Silva, L. S (2009). Mulheres em cena: as novas roupagens do primeiro damismo na Assistência Social. Dissertação de Mestrado, Programa de Pós-graduação em Serviço Social, Pontifícia Universidade Católica do Rio de Janeiro, Rio de Janeiro.

Souza, J. (2008). Sexualidade na terceira idade: uma discussão da Aids, Envelhecimento e Medicamentos para disfunção erétil. DST - J bras Doenças Sex Transm., 20(1), 59-64.

Souza, R. (2009). Sexualidade na Terceira Idade. Revista Educação, Meio Ambiente e Saúde; 4(1), 65-73.

Vieira, K. F. L. (2012). Sexualidade e qualidade de vida do idoso: desafios contemporâneos e repercussões psicossociais. Tese de Doutorado, Programa de Pós-graduação em Psicologia Social, Universidade Federal da Paraíba, João Pessoa, PB.

Vigotski, L. S. (2003). Pensamento e linguagem ( $3^{\mathrm{a}}$ ed.). São Paulo: Martins Fontes. (Original publicado em 1934)

Vigotsky, L. S. (2007). A formação social da mente: o desenvolvimento dos processos psicológicos superiores $\left(7^{\mathrm{a}}\right.$ ed.). São Paulo: Martins Fontes. (Original publicado em 1931)

Vitiello, N. \& Conceição, I. S. (1993). Manifestações da Sexualidade nas diferentes fases da vida. Revista Brasileira de Sexualidade, 4(1), 47-59.

Agências de fomento: Fundação de Amparo à Pesquisa do Estado do Amazonas (FAPEAM). Bolsa de mestrado, Programa de Apoio à Pós Graduação stricto sensu - POSGRAD, desenvolvido na Universidade Federal do Amazonas e Fundação Universidade do Amazonas (UFAM e FUA) - Edital: RESOLUÇÃO N. 016/2013 - POSGRAD 2013 - UFAM.

Submissão em: 30/06/2016

Revisão em: 28/04/2018

Aceite em: 09/07/2018 
Estephania de Lima Oliveira é psicóloga, mestre em Psicologia pela UFAM - Universidade Federal do Amazonas. Professora da Faculdade Maurício de Nassau. Pesquisadora do Laboratório de Desenvolvimento Humano e Educação da Faculdade de Psicologia da UFAM.

Endereço para correspondência.: PPGPsi/UFAM. Av.

General Rodrigo Otávio Jordão Ramos, 3000. Campus Universitário. Setor Sul, Bloco X. CEP 69077-000.

Manaus/AM, Brasil. https://orcid.org/0000-0003-4693-803X

E-mail: estephaniapsy@gmail.com

André Luiz Machado das Neves é professor da Escola Superior de Ciências da Saúde da Universidade do Estado do Amazonas. Mestre em Psicologia pela Universidade Federal do Amazonas. Doutorando em Saúde Coletiva pelo Instituto de Medicina Social da Universidade do Estado do Rio de Janeiro. Pesquisador do Laboratório de Desenvolvimento Humano e Educação da Faculdade de Psicologia da UFAM.

http://orcid.org/0000-0001-7400-7596 E-mail: andre machadostm@hotmail.com

Iolete Ribeiro da Silva é psicóloga, doutora em Psicologia pela Universidade de Brasília. Professora do programa de pós-graduação em Psicologia e do programa de pósgraduação em Educação da UFAM. Coordenadora do

Laboratório de Desenvolvimento Humano e Educação da Faculdade de Psicologia da UFAM. https://orcid.org/0000-0002-9416-6866 E-mail: iolete.silva@gmail.com 